\section{A influência histórica no surgimento dos princípios da bioética}

\author{
Pereira, Gabriela Strini ${ }^{1}$ \\ Araujo, Ana Carolina Souza Sisnando De \\ Silva, Ana Luiza Antony Gomes De Matos Da Costa \\ Sousa, Kamila Catta Preta Carneiro De \\ Ribeiro, Leonardo Melo Name \\ Andrade, Isabella Gonçalves \\ ${ }^{1}$ Acadêmico(a) do curso de Medicina - Centro Universitário \\ de Brasília - UniCEUB/DF. Autor a contatar: \\ gabrielastrini@gmail.com
}

PAlaVRaS CHAVE: Bioética; Fatores Históricos; Direitos Humanos; Consentimento.

INTRODUÇÃO: A investigação em pesquisa mostra-se de grande interesse social desde a Antiguidade. A evolução da humanidade trouxe a necessidade de novos conhecimentos e aprimoramento dos antigos, visto as novas ferramentas à disposição. A bioética apresenta-se como uma forma de ética aplicada, a fim de estabelecer limites a essa busca, sem ultrapassar barreiras ético-morais ${ }^{1}$. Seu surgimento está associado a pessoas e fatos específicos que mudaram o curso da normatização em pesquisa a partir do impacto social desses eventos. O Tribunal de Nuremberg ${ }^{2}$ - responsável pelo julgamento de criminosos da Segunda Guerra Mundial, a maioria médicos que realizaram experimentos em seres humanos na Alemanha nazista - mostrou ao mundo que os princípios profissionais isolados não são confiáveis, havendo necessidade de criar um limite seguro com barreiras visíveis no controle da experimentação. $\mathrm{O}$ artigo feito por Henry Beecher mostrou que as violações éticas não estavam no passado nem eram exclusividade do nazismo ${ }^{3}$. Ele analisou a compilação de 22 relatos de pesquisas em condições pouco respeitosas, como a investigação dos efeitos da hepatite por infecção proposital em crianças com retardo mental, com consentimento dos pais, mostrando uma exploração de vulnerável. O Estudo Tuskegee, iniciado em 1932 teve grande repercussão nos Estados Unidos apenas em 1972, quando foi revelado pela mídia ${ }^{4}$. Seu objetivo era o desenvolvimento de um projeto com negros sifilíticos a fim de criar evidências para a Medicina Racial sobre a evolução da história natural da doença. MÉTODO: Foi realizada uma revisão integrativa da literatura. Todas as análises foram baseadas em estudos publicados identificados em uma série de bancos de dados médicos, bibliográficos e cooperativos, incluindo Scientific Electronic Library Online (SciELO), Medical Literature Analysis and Retrieval System Online (MEDLINE) pesquisados no PubMed e no Google Scholar. Os descritores foram "história da bioética", "the beginning of bioethics", "fatores influentes no surgimento dos princípios bioética" "historical birth of bioethics". RESULTADOS: As pesquisas experimentais que vão contra os princípios bioéticos se baseiam na ampliação do conhecimento sem benefícios aos sujeitos da pesquisa e à comunidade. $\mathrm{O}$ Código de Nuremberg ${ }^{2}$ propôs recomendações éticas a serem seguidas em pesquisas com seres humanos. A repercussão das atrocidades cometidas ao longo da Segunda Guerra foi tamanha que, em 1948, a ONU adotou a Declaração dos Direitos Humanos, iniciando uma nova era. O Estudo Tuskegee levou à criação da Comissão Nacional para a Proteção de Sujeitos Humanos na Pesquisa Biomédica e Comportamental para normatizar as ações médicas em pesquisas experimentais, e 4 anos após sua criação instituiuse o Relatório Belmont (1979). CONCLUSÃO: O nascimento da bioética tem como marco inicial uma compilação de fatores históricos que culminaram na necessidade de princípios que norteassem as ações de profissionais visando respeito e dignidade humanos. O estabelecimento da ética em pesquisa foi amplamente debatido no Tribunal de Nuremberg, discutindo-se os direitos dos pacientes, como o consentimento voluntário para realização de pesquisas. Algumas décadas depois, o Relatório de Belmont ${ }^{4}$ - um documento importante para a bioética - descreveu pela primeira vez, oficialmente, os princípios básicos da bioética e a normatização do consentimento livre e esclarecido do paciente.

AGRADECIMENTOS: Ao Centro Universitário de Brasília (UniCEUB)

\section{REFERÊNCIAS}

[1] PESSINI L. As origens da bioética: do credo bioético de Potter ao imperativo bioético de Fritz Jahr. Rev bioét (Impr.) 2013; 21 (1): 9-19.

[2] SHUSTER E. Fifty years later: the significance of the nuremberg code. The New England Journal of Medicine (1997).

[3] STARK L. The unintended ethics of Henry K Beecher. The art of medicine June 11, $2016 \mathrm{Vol}$ 387, ISSUE 10036.

[4] LOPES J. A. .Bioética - uma breve história:de Nuremberg (1947) a Belmont (1979). Revista Médica de Minas Gerais 2014; 24(2): 262-273. 